\title{
Estrogen Can Modulate Menopausal Women's Heart Rate Variability
}

\author{
S.-G. YANG ${ }^{1}$, M. MLČEK ${ }^{2}$, O. KITTNAR ${ }^{2}$ \\ ${ }^{1}$ Cardiology Department of Taiwan Hospital, Republic of China, ${ }^{2}$ Institute of Physiology, First \\ Faculty of Medicine, Charles University in Prague, Prague, Czech Republic
}

Received March 16, 2013

Accepted July 10, 2013

\section{Summary}

The aim of our study was to compare the responses of heart rate variability (HRV) with two different types of hormonal substitution therapy (HT) in post-menopausal women (crosssectional study) and to reveal an effect of HT shortly after beginning of its administration (follow-up study). To elucidate the influence of menopause and effects of different protocols of a HT on autonomic control of heart rate, we evaluated the heart rate variability (HRV) in 5 groups: premenopausal women $(n=140)$, postmenopausal women without HT $(n=360)$, women on HT with conjugated estrogen only $(n=168)$, women on continuous combined estrogen-progesterone HT ( $n=117)$, and men $(n=140)$. Frequency-domain of short-term stationary $R-R$ intervals was performed to evaluate the total variance, low frequency power (LF; 0.04-0.15 Hz), high frequency power (HF; 0.15-0.40 Hz), portion of low frequency power (LF\%) and ratio of $\mathrm{LF}$ to $\mathrm{HF}$ (LF/HF). Significantly lower portion of the LF was found in premenopausal women $[46.9( \pm 2.7) \mathrm{nu}]$ when compared to untreated postmenopausal women $[54.3( \pm 2.9) \mathrm{nu}]$ and men [55.2 $( \pm 3.0) \mathrm{nu}$. Treatment by estrogen only was proved to decrease the LF\% $[40.1( \pm 2.1)$ nu] while no effect on HRV was observed in women treated with combination of estrogen and progesterone $[57.2( \pm 3.1) n u]$. Also the HF was lower in postmenopausal women $\left[4.16( \pm 0.16) \mathrm{ms}^{2}\right]$ than in premenopausal women $\left[4.79( \pm 0.22) \mathrm{ms}^{2}\right]$ and women treated with estrogen only $\left[4.98( \pm 0.25) \mathrm{ms}^{2}\right]$ while in women treated with combined hormonal therapy the average value [3.99 $\left.( \pm 0.21) \mathrm{ms}^{2}\right]$ did not significantly differ from that of untreated postmenopausal women. The follow-up study also proved increase of high frequency power already after two months of estrogen substitution therapy $\left[4.86( \pm 0.14) \mathrm{ms}^{2}\right.$ vs. $4.19( \pm 0.15)$ $\left.\mathrm{ms}^{2}\right]$. These results suggest that higher vagal modulation of heart rate that seems typical for younger women becomes after menopause similar to that of men. We also proved a positive shift of HRV parameters toward more beneficial values as for a cardiovascular risk in postmenopausal women treated with estrogens but not in those treated by combined estrogen progesterone substitution therapy.

\section{Key words}

Menopause - Hormone replacement therapy - Heart rate variability

\section{Corresponding author}

Otomar Kittnar, Institute of Physiology, First Faculty of Medicine, Charles University in Prague, Albertov 5, 12800 Prague 2, Czech Republic. E-mail: otomar.kittnar@staff.cuni.cz

\section{Introduction}

Physiological menopause occurs as a part of a woman's normal aging process being based on the natural cessation of estradiol and progesterone production by the ovaries. The dramatic fall in circulating estrogens levels at menopause impacts many tissues including cardiovascular system. During peri-menopausal period the effect of decreasing production of ovarian hormones is modulated by an increase in circulating follicle stimulating hormone (FSH) and luteinizing hormone (LH) levels because of a feed-back stimulation of their secretion.

Because the incidence of coronary heart disease (CHD) rises significantly after menopause, it has been hypothesized that women's CHD advantage before menopause (in comparison to men of the same age) could be due to the protective effects of estrogens (Lerner and Kannel 1986). Based on this hypothesis many animal and observational studies were designed to elucidate the effect of postmenopausal hormone therapy (HT). The results of these studies have suggested a benefit of the HT with regard to the development of CHD (Adams et al. 
1990, Grodstein et al. 1996, Arnal et al. 2006). On the other hand, some large prospective studies and prevention studies failed to confirm any estrogen-related cardioprotective effect (Hulley et al. 1998, Rossouw et al. 2002). Controversial results continued to be reported since early nineties until today. While some studies found reduction in the incidence of CHD and in mortality from cardiovascular diseases (Stampfer et al. 1991) some other studies failed to provide any evidence for an independent role of estradiol levels in determining CHD in postmenopausal women (Barret-Connor et al. 1995, Rexrode et al. 2003, Lee et al. 2010, Chen et al. 2011) and some studies even found positive association of endogenous estradiol with the risk of CHD among women above 65 years of age (Scarabin-Carré et al. 2012). The positive effect of estrogen is usually explained by its role in affecting lipid and lipoprotein metabolism (Ross et al. 1989) and by reduction of an arterial blood pressure (De Meersman et al. 1998, Vongpatanasin et al. 2001). Negative effect is explained by positive relation of estrogens to some cardiovascular risk factors such as obesity (Baglietto et al. 2009), glucose tolerance status (Ding et al. 2007, Golden et al. 2007) or C-reactive protein level (Stork et al. 2008, Maggio et al. 2011) in postmenopausal women. Moreover it is questionable if a timing of hormone initiation might influence the HT effect on CHD risk, with a decrease in CHD risk for women starting to use HT close to menopause and with a higher risk for women starting to use HT later (ScarabinCarré et al. 2012).

In spite of the fact that etiology of many postmenopausal symptoms is not yet clear, the dominating cause of them is obviously a deficit of ovarian hormones. Endocrine and metabolic symptoms developing during peri-menopausal period are accompanied by changes in autonomic functions and particularly the presence of cardiovascular symptoms in peri-menopausal period was suggested to be associated with the decrease of cardiac autonomic nervous system regulatory function (Rys et al. 2006). The role of the autonomic nervous system in affecting the cardiovascular system in peri- and postmenopausal period and the role of prospective effect of HT on these changes thus remains to be elucidated. Therefore, the aim of our study was to compare the responses of heart rate variability (HRV) with two different types of HT in post-menopausal women (crosssectional study) and to reveal an effect of HT shortly after beginning of its administration (follow-up study).

HRV refers to the beat-to-beat alterations in heart rate. Under resting conditions, the ECG of healthy individuals exhibits periodic variation in R-R intervals. Frequency-domain analysis of HRV allows revealing its spectral components. There are two major components contained in the HRV spectrum: The high frequency component HF (0.15-0.40 Hz) equivalent to the respiratory sinus arrhythmia represents parasympathetic control of the heart rate as seen from clinical and experimental observations of autonomic maneuvers such as electrical vagal stimulation or muscarinic receptor blockade (Fouad et al. 1984). The low frequency component LF (0.04$0.15 \mathrm{~Hz}$ ) is not completely understood and it appears to be mediated by both sympathetic and parasympathetic nerves (Malliani et al. 1991, Pagani et al. 1997).

\section{Methods}

The cross-sectional study was performed on 925 volunteers. The whole cohort was composed of three groups: premenopausal women, postmenopausal women (at least two years from the last menstrual period) and men at the same age as postmenopausal women (Table 1). The volunteers were recruited from healthy

Table 1. Characteristics of the groups involved in our study.

\begin{tabular}{|c|c|c|c|c|c|c|c|}
\hline & $\mathbf{n}$ & Age & $\begin{array}{l}\text { Height } \\
\text { (cm) }\end{array}$ & $\begin{array}{l}\text { Weight } \\
\text { (kg) }\end{array}$ & $\begin{array}{c}\text { SBP } \\
(\mathbf{m m H g})\end{array}$ & $\begin{array}{c}\text { DBP } \\
(\mathbf{m m H g})\end{array}$ & MP age \\
\hline Men & 140 & $60.8 \pm 2.1^{*}$ & $161.8 \pm 1.5$ & $68.3 \pm 2.3$ & $121.6 \pm 2.2$ & $77.1 \pm 1.7$ & - \\
\hline PreMP & 140 & $42.2 \pm 1.4$ & $156 \pm 1.4^{*}$ & $61.9 \pm 4.5$ & $111.4 \pm 3.1$ & $71.9 \pm 3.1$ & - \\
\hline PostMP & 360 & $58.2 \pm 0.8^{*}$ & $151.4 \pm 1.0^{*}$ & $64.4 \pm 1.1$ & $121.6 \pm 2.0$ & $75.0 \pm 1.4$ & $50.1 \pm 0.6$ \\
\hline$E$ & 170 & $58.2 \pm 1.1^{*}$ & $151.5 \pm 1.2^{*}$ & $64.2 \pm 2.0$ & $120.2 \pm 3.3$ & $74.0 \pm 1.6$ & $49.1 \pm 0.8$ \\
\hline$E+P$ & 120 & $56.1 \pm 0.8^{*}$ & $153.2 \pm 1.5^{*}$ & $64.9 \pm 2.4$ & $122.2 \pm 2.4$ & $76.6 \pm 2.1$ & $47.4 \pm 1.2$ \\
\hline
\end{tabular}

Values are presented as means $\pm \mathrm{SE} ; \mathrm{n}$ - number of subjects/group; SBP - systolic blood pressure; DBP - diastolic blood pressure; preMP - premenopausal women; postMP - postmenopausal women without HRT; E - postmenopausal women with estrogen replacement therapy only; $\mathrm{E}+\mathrm{P}$ - postmenopausal women with combined estrogen and progesterone HRT. 
population who live in the same Datong District of Taipei, Taiwan, R.O.C. The group of postmenopausal women was divided randomly into three subgroups: women without any hormonal treatment, women treated by conjugated estrogen (Premarin at $0.625 \mathrm{mg} / \mathrm{day}$ ) and women receiving combined hormone replacement (Covina at estradiol $2 \mathrm{mg}+$ norethisterone acetate $1 \mathrm{mg} /$ day). Both subgroups with HT were treated continuously, group E (estrogen only) continuously by conjugated estrogen, group $\mathrm{E}+\mathrm{P}$ repeatedly by estrogen only in first 14 days of 28-days periods and by combination of estrogen and progestin in second halves of 28-days periods.

The follow-up study included only postmenopausal woman with estrogen replacement therapy and postmenopausal woman with combined HT receiving the hormone therapy for at least two consecutive months.

The exclusion criteria were cardiovascular diseases, arterial hypertension, diabetes mellitus, asthma, smoking, neurological or psychiatric diseases and any medication that have been reported to affect heart rate (like for instance autonomic blockers). Also postmenopausal women receiving HT or contraceptives before menopausal symptoms were excluded from the study. Before the experiment, objects had no participation in any strenuous exercise, drinking, smoking, drinking caffeinated beverages and taking sleeping pills or tranquilizers.

A detailed overall examination including basic biochemistry was performed before the beginning of the study and all participants were informed about the purpose of the study and all procedures before obtaining their written consent. All ECG examinations were performed between 8 a.m. and 3 p.m. Before every ECG examination the participants were ordered rest in a supine position for at least 5 minutes in a separate quiet room. One electrode was affixed to the sternal edge of the left second intercostal space, the other one to the midclavicular line in the fourth intercostal space. The examination was realized at standard conditions under complete physical and mental rest, participants were asked to keep laying quietly and breathing normally but not to go to sleep.

ECG signals were recorded by an 8-bit analogue to digital convertor with a sampling rate of $256 \mathrm{~Hz}$, analyzed on-line, and stored on the IBM-PC hard drive. Software used for processing of the signal first identified each QRS complex by a spike detection algorithm and then excluded all premature beats and all beats not corresponding to the standard QRS template. Nonparametric spectral analysis of the HRV was performed using fast Fourier transformation (FFT) and for attenuation of the leakage effect a Hamming operator was used. Such obtained power spectrum was computed to get standard frequency domain measurements (Task Force of the European Society of Cardiology and the North American Society of Pacing and Electrophysiology 1996) which include: total variance, low-frequency power (LF), high-frequency power (HF) and low-frequency to highfrequency power ratio (LF/HF). All these variables were then logarithmically transformed in order to correct for the skewness of the distribution (Kuo et al. 1999). The data were expressed as means \pm standard error. For statistical analysis one-way ANOVA and Fisher's least significant difference test were used. Differences were considered to be statistically significant at $\mathrm{p}<0.05$.

\section{Results}

The average heart rate $( \pm \mathrm{SD})$ in the group of women treated by conjugated estrogen [64.6 $( \pm 3.5)$ $\min ^{-1}$ ] was significantly lower than in premenopausal women $\left[73.1( \pm 3.9) \mathrm{min}^{-1}\right]$ and also than in women treated by the combined hormone replacement therapy $\left[81.4( \pm 4.6) \mathrm{min}^{-1}\right]$. The heart rate of women treated by conjugated estrogen was comparable with that of men. No significant difference was observed between premenopausal women and postmenopausal women without any hormonal treatment (Fig. 1).

Significantly lower portion of the low frequency power $(\mathrm{LF} \%)$ was found in premenopausal women [46.9 $( \pm 2.7) \mathrm{nu}]$ when compared to untreated

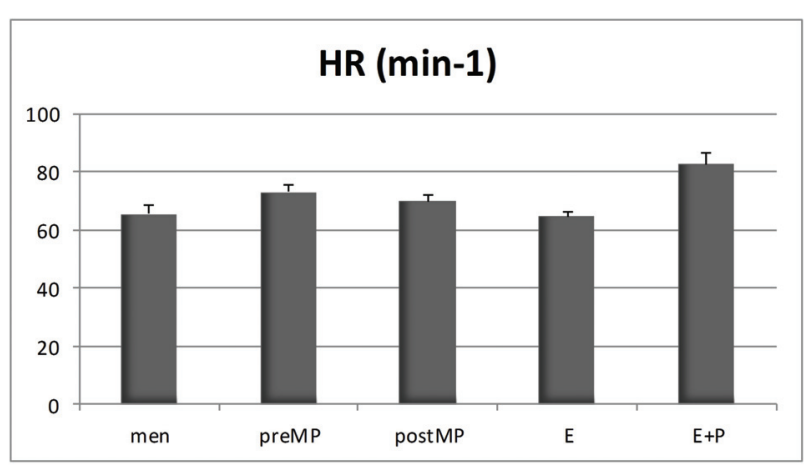

Fig. 1. Average heart rate $( \pm S D)$ in studied groups (preMP premenopausal women; postMP - postmenopausal women without HRT; E - postmenopausal women with estrogen replacement therapy only; $\mathrm{E}+\mathrm{P}$ - postmenopausal women with combined estrogen and progesterone HRT). 


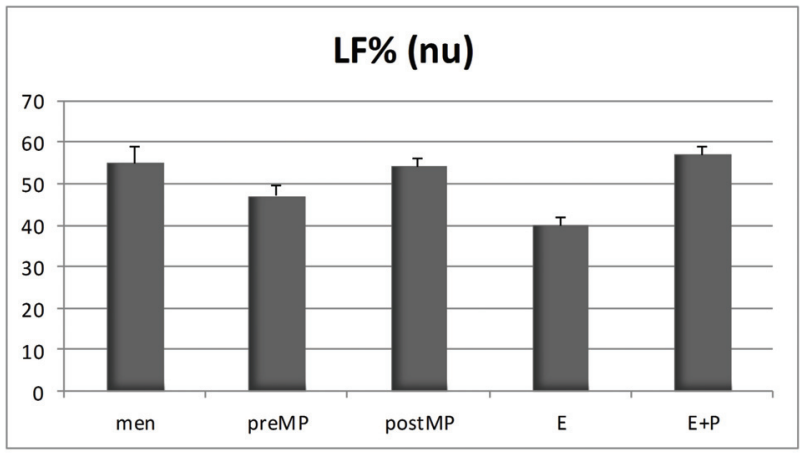

Fig. 2. Average portion of the low frequency power $( \pm S D)$ in studied groups (preMP - premenopausal women; postMP postmenopausal women without HRT; E - postmenopausal women with estrogen replacement therapy only; E+P postmenopausal women with combined estrogen and progesterone $\mathrm{HT}$ ).

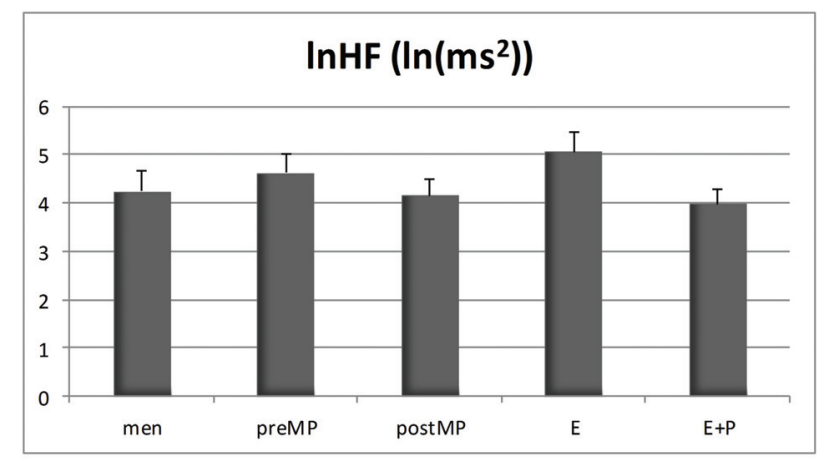

Fig. 3. Average high frequency power after natural logarithm transformation $( \pm S D)$ in studied groups (preMP - premenopausal women; postMP - postmenopausal women without HRT; E postmenopausal women with estrogen replacement therapy only; $\mathrm{E}+\mathrm{P}$ - postmenopausal women with combined estrogen and progesterone $\mathrm{HT}$ ).

postmenopausal women $[54.3( \pm 2.9) \mathrm{nu}]$ and men [55.2 $( \pm 3.0) \mathrm{nu}]$. Treatment by estrogen alone significantly decreased the low frequency power ratio [40.1 $( \pm 2.1) \mathrm{nu}]$ while no similar effect was observed in women treated with combination of estrogen and progesterone [57.2 $( \pm 3.1) \mathrm{nu}$ ] (Fig. 2). Also the high frequency power was lower in postmenopausal women $\left[4.16( \pm 0.16) \mathrm{ms}^{2}\right]$ than in premenopausal women $\left[4.79( \pm 0.22) \mathrm{ms}^{2}\right]$ and women treated with estrogen only [4.98 $\left.( \pm 0.25) \mathrm{ms}^{2}\right]$ while in women treated with combined hormonal therapy the average value $\left[3.99( \pm 0.21) \mathrm{ms}^{2}\right]$ did not significantly differ from that of untreated postmenopausal women (Fig. 3). The corresponding results were consistently found in lowfrequency to high-frequency power ratio: the values in premenopausal women $[0.04( \pm 0.12)]$ and women treated by estrogen $[-0.25( \pm 0.16)]$ were significantly lower than values found in untreated postmenopausal women

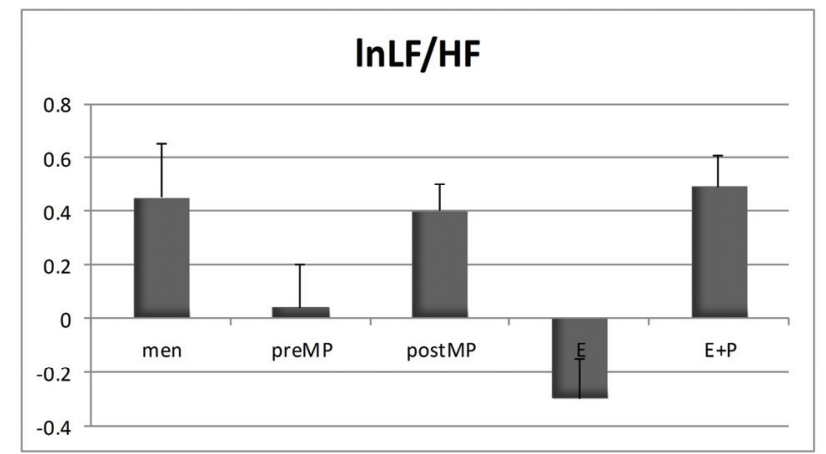

Fig. 4. Average low-frequency to high-frequency power ratio $( \pm S D)$ in studied groups (preMP - premenopausal women; postMP - postmenopausal women without HRT; E postmenopausal women with estrogen replacement therapy only; $\mathrm{E}+\mathrm{P}$ - postmenopausal women with combined estrogen and progesterone $\mathrm{HT}$ ).

$[0.36( \pm 0.12)]$ and women treated by combined hormonal therapy $[0.48( \pm 0.16)]$ (Fig. 4).

The follow-up study also proved the increase of high frequency power already after two months of estrogen substitution therapy $\left[4.86( \pm 0.14) \mathrm{ms}^{2}\right.$ vs. $\left.4.19( \pm 0.15) \mathrm{ms}^{2}\right]$.

\section{Discussion}

The present study aimed to compare the responses of HRV with two different types of hormonal substitution therapy (HT) in postmenopausal women (cross-sectional study) and to reveal an effect of HT shortly after beginning of its administration (follow-up study). Simultaneously we compared the HRV between postmenopausal women and men at corresponding age. The characteristics of the groups involved in our study are summarized in Table 1, the only significant differences are in the age of premenopausal women in comparison to all other groups and in the body height of men in comparison to all women groups.

Decline in short-term indexes of HRV is associated both with ageing and with declined estrogen levels after menopause (Neves et al. 2007). Higher highfrequency power in premenopausal women in comparison to age-matched men was found by Kuo and al. (1999). This finding was confirmed by Liu et al. (2003) and moreover they have proved that these gender-related differences disappear after menopause. Our results fully correspond to these findings as we have not found any difference between postmenopausal women and men, but significant differences between premenopausal women and both men and postmenopausal women. 
These results suggest that higher vagal modulation of heart rate that seems to be typical for younger women becomes after menopause similar to that of men. Responsibility for this phenomenon lies fully in ovarian hormones what was reported by Mercuro et al. (2000) who searched for effect of oophorectomy in premenopausal women on HRV. In their study comparing healthy women before and after oophorectomy with agematched women who underwent hysterectomy with ovarian conservation they concluded that surgical menopause induced a decline in cardiac vagal modulation with a recovery of the baseline condition after 3 months of estrogen replacement therapy. This result suggests a crucial role of estrogen in the autonomic nervous control of the heart rate. On the other hand it is known that progesterone has a number of potential adverse effects on the cardiovascular system (Rosano GM 2000, Lantto et al. 2012) and our results support the concept that progesterone effect attenuates the benefit of unopposed estrogen replacement therapy in post-menopausal women. In order to confirm our hypothesis of a reverse effect of progesterone on HRV we used different types of HT. Although there are many possible HT regimens described in literature we choose only two standard prescriptions in order to make the study transparent. For comparison of effects of these two types of HT on the heart rate autonomic control we used spectral analysis of HRV. This method has been used since the late 1960s. Power spectral density analysis provides information on how power (variance) distributes as a function of frequency. (Carter et al. 2003). The advantages of nonparametric methods, such as the fast Fourier transform, are the simplicity of the algorithm used and the high processing speed. HRV as a powerful tool for the estimation of cardiac autonomic modulations is associated with three major physiological factors, which primarily reflect changing level of both parasympathetic and sympathetic neural control of the heart: oscillatory fluctuations in blood pressure, frequency oscillations due to thermal regulation and respiration. HRV may therefore be considered an output variable of a feedback network that is continuously monitored and regulated by the autonomic nervous system.

Our study showed that HRV differences among the groups were related to the differences of heart rate. This phenomenon could have both mathematical (shorter RR intervals mean that also their fluctuations are lower and thus also less identifiable) and physiological background (tachycardia is generally associated with increased sympathetic and decreased parasympathetic tone). We suppose that decreased heart rate and simultaneously increased high frequency power and very low value of $\operatorname{lnLF} / \mathrm{HF}$, that was identified in our study, fully correspond to the described changes in the tones of the autonomic nervous system. Moreover it was proved that clinical usefulness of HRV is relatively independent on the heart rate differences (Kautzner et al. 1998).

Animal studies and observational studies have suggested that the use of HT in postmenopausal women could be beneficial with regards to the development of CHD (Adams et al. 1990, Grodstein et al. 1996, Arnal et al. 2006). On the other hand a possible association between estrogens and higher risk of cardiovascular mortality started to be discussed in many recent studies both with negative (Barret-Connor and Goodman-Gruen 1995) and positive (Scarabin-Carré et al. 2012) conclusions. One possible reason for different results could be the time of measurement. Most published measurements as well as our measurements were performed between 8 a.m. and 3 p.m. when sympathetic activity dominates over the parasympathetic one. One of recently published papers studied the effect of estrogen HT on nocturnal HRV and found that HT has a slightly but distinctively attenuating effect on some nocturnal nonlinear measures of HRV, especially on complexity of heart rate dynamics, suggesting that estrogen HT may have potentially deleterious effects on cardiovascular health during sleep (Virtanen et al. 2008). Another possible reason for different results could be different age of postmenopausal women in these studies. While in younger postmenopausal women no association between estradiol levels and cardiovascular risk was found in postmenopausal women over 65 years a positive association between estrogens and progression of atherosclerotic process was identified. Our results proved a positive shift of HRV parameters toward more beneficial values regarding the cardiovascular risk in postmenopausal women treated with estrogens but not in women treated by combined therapy with estrogens and progesteron. But more particularly prospective studies are needed to confirm or definitely reject the theory of protective effects of estrogen HT in postmenopause or to define an age-limit for beneficial effects of this therapy.

\section{Conflict of Interest}

There is no conflict of interest.

\section{Acknowledgements}

Supported by PRVOUK-P38/LF1/10 and SVV-2012264504. 


\section{References}

ADAMS MR, KAPLAN JR, MANUCK SB, KORITNIK DR, PARKS JS, WOLFE MS, CLARKSON TB: Inhibition of coronary artery atherosclerosis by 17-beta estradiol in ovariectomized monkeys. Lack of an effect of added progesterone. Arteriosclerosis 10: 1051-1057, 1990.

ARNAL JF, DOUIN-ECHINARD V, BROUCHET L, TREMOLLIERES F, LAURELL H, LENFANT F, GADEAU AP, GUERY JC, GOURDY P: Understanding the oestrogen action in experimental and clinical atherosclerosis. Fundam Clin Pharmacol 20: 539-548, 2006.

BAGLIETTO L, ENGLISH DR, HOPPER JL, MACINNIS RJ, MORRIS HA, TILLEY WD, KRISHNAN K, GILES GG: Circulating steroid hormone concentrations in postmenopausal women in relation to body size and composition. Breast Cancer Res Treat 115: 171-179, 2009.

BARRETT-CONNOR E, GOODMAN-GRUEN D: Prospective study of endogenous sex hormones and fatal cardiovascular disease in postmenopausal women. BMJ 311: 1193-1196, 1995.

CARTER JB, BANISTER EW, BLABER AP: Effects of endurance exercise on autonomic control of heart rate. Sports Med 33: 33-46, 2003.

CHEN Y, ZELENIUCH-JACQUOTTE A, ARSLAN AA, WOJCIK O, TONIOLO P, SHORE RE, LEVITZ M, KOENIG KL: Endogenous hormones and coronary heart disease in postmenopausal women. Atherosclerosis 216: 414-419, 2011.

DE MEERSMAN RE, ZION AS, GIARDINA EG, WEIR JP, LIEBERMAN JS, DOWNEY JA: Estrogen replacement, vascular distensibility, and blood pressures in postmenopausal women. Am J Physiol 274: H1539-H1544, 1998.

DING EL, SONG Y, MANSON JE, RIFAI N, BURING JE, LIU S: Plasma sex steroid hormones and risk of developing type 2 diabetes in women: a prospective study. Diabetologia 50: 2076-2084, 2007.

FOUAD FM, TARAZI RC, FERRARIO CM, FIGHALY S, ALICANDRI C: Assessment of parasympathetic control of heart rate by a noninvasive method. Am J Physiol 246: H838-H842, 1984.

GOLDEN SH, DOBS AS, VAIDYA D, SZKLO M, GAPSTUR S, KOPP P, LIU K, OUYANG P: Endogenous sex hormones and glucose tolerance status in postmenopausal women. $J$ Clin Endocrinol Metab 92: 1289-1295, 2007.

GRODSTEIN F, STAMPFER MJ, MANSON JE, COLDITZ GA, WILLETT WC, ROSNER B, SPEIZER FE, HENNEKENS CH: Postmenopausal estrogen and progestin use and the risk of cardiovascular disease. $N$ Engl J Med 335: 453-461, 1996.

HULLEY S, GRADY D, BUSH T, FURBERG C, HERRINGTON D, RIGGS B, VITTINGHOFF E: Randomized trial of estrogen plus progestin for secondary prevention of coronary heart disease in postmenopausal women: Heart and Estrogen/progestin Replacement Study (HERS) Research Group. JAMA 280: 605-613, 1998.

KAUTZNER J, ST'OVÍCEK P, ANGER Z, SAVLÍKOVÁ J, MALIK M: Utility of short-term heart rate variability for prediction of sudden cardiac death after acute myocardial infarction. Acta Univ Palacki Olomuc Fac Med 141: 69-73, 1998.

KUO TBJ, LIN T, YANG CCH, LI CL, CHEN CF, CHOU P: Effect of aging on gender differences in neural control of heart rate. Am J Physiol 277: H2233-H2239, 1999.

LANTTO H, HAAPALAHTI P, TUOMIKOSKI P, VIITASALO M, VÄÄNÄNEN H, SOVIJÄRVI AR, YLIKORKALA O, MIKKOLA TS: Vasomotor hot flashes and heart rate variability: a placebo-controlled trial of postmenopausal hormone therapy. Menopause 19: 82-88, 2012.

LEE JS, YAFFE K, LUI LY, CAULEY J, TAYLOR B, BROWNER W, CUMMINGS S: Prospective study of endogenous circulating estradiol and risk of stroke in older women. Arch Neurol 67: 195-201, 2010.

LERNER DJ, KANNEL WB: Patterns of coronary heart disease morbidity and mortality in the sexes: a 26-year followup of the Framingham population. Am Heart J 111: 383-390, 1986.

LIU CC, KUO TB, YANG CC: Effects of estrogen on gender-related autonomic differences in humans. Am J Physiol 285: H2188-H2193, 2003. 
MAGGIO M, CEDA GP, LAURETANI F, BANDINELLI S, CORSI AM, GIALLAURIA F, GURALNIK JM, ZULIANI G, CATTABIANI C, PARRINO S, ABLONDI F, DALL'AGLIO E, CERESINI G, BASARIA S, FERRUCCI L: SHBG, sex hormones, and inflammatory markers in older women. J Clin Endocrinol Metab 96: 1053-1059, 2011.

MALLIANI A, PAGANI M, LOMBARDI F, CERUTTI S: Cardiovascular neural regulation explored in the frequency domain. Circulation 84: 482-492, 1991.

MERCURO G, PODDA A, PITZALIS L, ZONCU S, MASCIA M, MELIS GB, ROSANO GB: Evidence of a role of endogenous estrogen in the modulation of autonomic nervous system. Am J Cardiol 85: 787-789, 2000.

NEVES VF, SILVA DE SÁ MF, GALlO L Jr, CATAI AM, MARTINS LE, CRESCÊNCIO JC, PERPÉTUO NM, SILVA E: Autonomic modulation of heart rate of young and postmenopausal women undergoing estrogen therapy. Braz J Med Biol Res 40: 491-499, 2007.

PAGANI M, MONTANO N, PORTA A, MALLIANI A, ABBOUD FM, BIRKETT C, SOMERS VK: Relationship between spectral components of cardiovascular variabilities and direct measures of muscle sympathetic nerve activity in humans. Circulation 95: 1441-1448, 1997.

REXRODE KM, MANSON JE, LEE IM, RIDKER PM, SLUSS PM, COOK NR, BURING JE: Sex hormone levels and risk of cardiovascular events in postmenopausal women. Circulation 108: 1688-1693, 2003.

ROSANO GM, SARAIS C, ZONCU S, MERCURO G: The relative effects of progesterone and progestins in hormone replacement therapy. Hum Reprod 15 (Suppl 1): 60-73, 2000.

ROSS RK, PAGANINI-HILL A, MACK TM, HENDERSON BE: Cardiovascular benefits of estrogen replacement therapy. Am J Obstet Gynecol 160: 1301-1306, 1989.

ROSSOUW JE, ANDERSON GL, PRENTICE RL, LACROIX AZ, KOOPERBERG C, STEFANICK ML, JACKSON RD, BERESFORD SA, HOWARD BV, JOHNSON KC, KOTCHEN JM, OCKENE J: Risks and benefits of estrogen plus progestin in healthy postmenopausal women: principal results from the Women's Health Initiative randomized controlled trial. JAMA 288: 321-333, 2002.

RYS A, RAS A, KOGUT P, THOR PJ: Menopausal changes in circadian heart rate variability. Folia Med Cracov 47: 69-78, 2006.

SCARABIN-CARRE V, CANONICO M, BRAILLY-TABARD S, TRABADO S, DUCIMETIERE P, GIROUD M, RYAN J, HELMER C, PLU-BUREAU G, GUIOCHON-MANTEL A, SCARABIN PY: High level of plasma estradiol as a new predictor of ischemic arterial disease in older postmenopausal women: the three-city cohort study. J Am Heart Assoc 1: e001388, 2012.

STAMPFER MJ, COLDITZ GA, WILLETT WC, MANSON JE, ROSNER B, SPEIZER FE, HENNEKENS CH: Postmenopausal estrogen therapy and cardiovascular disease. Ten-year follow-up from the nurses' health study. N Engl J Med 325: 756-762, 1991.

STORK S, BOTS ML, GROBBEE DE, VAN DER SCHOUW YT: Endogenous sex hormones and C-reactive protein in healthy postmenopausal women. J Intern Med 264: 245-253, 2008.

TASK FORCE OF THE EUROPEAN SOCIETY OF CARDIOLOGY AND THE NORTH AMERICAN SOCIETY OF PACING AND ELECTROPHYSIOLOGY: Heart rate variability: standards of measurement, physiological interpretation and clinical use. Circulation 93: 1043-1065, 1996.

VIRTANEN I, EKHOLM E, POLO-KANTOLA P, HIEKKANEN H, HUIKURI H: Postmenopausal estrogen therapy modulates nocturnal nonlinear heart rate dynamics. Menopause 15: 693-697, 2008.

VONGPATANASIN W, TUNCEL M, MANSOUR Y, ARBIQUE D, VICTOR RG: Transdermal estrogen replacement therapy decreases sympathetic activity in postmenopausal women. Circulation 103: 2903-2908, 2001. 